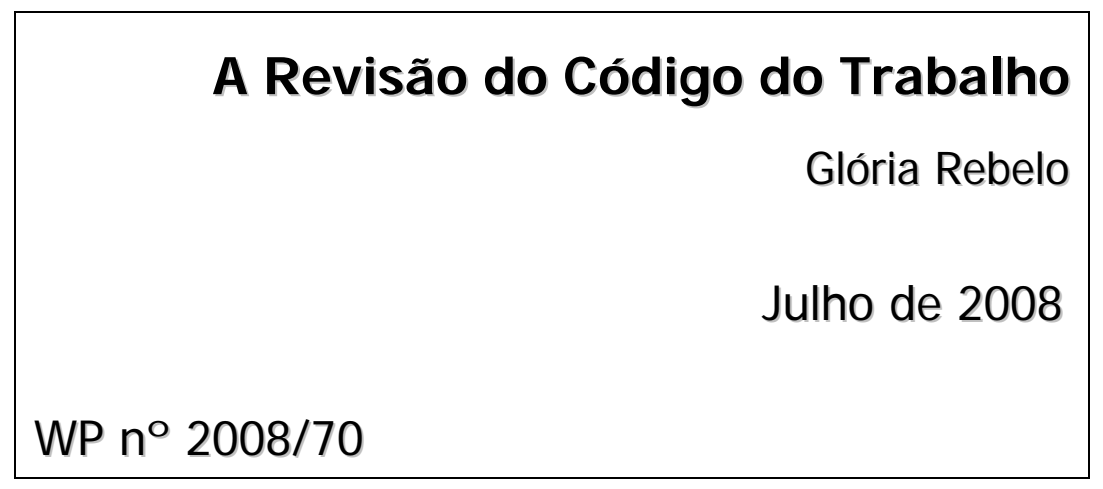

DOCUMENTO DE TRABALHO

WORKI NG PAPER 
Abstrat

1. O CONTEXTO SOCIOECONÓMICO DA REVISÃO 3

2. OS GRANDES PROPÓSITOS DA REVISÃO LEGISLATIVA 6

2.1. COMBATER A PRECARIEDADE E PROMOVER A QUALIDADE DO EMPREGO 6

2.1.1. CONTRATAÇÃO A TERMO E TRABALHO TEMPORÁRIO

\footnotetext{
${ }^{1}$ Licenciada (1992) e Mestre (1998) pela Faculdade de Direito da Universidade de Lisboa e Doutora (2002) pelo Instituto Superior de Economia e Gestão da Universidade Técnica de Lisboa. Investigadora do Dinâmia - Centro de Estudos sobre a Mudança Socioeconómica. Email: gloria.rebelo@netcabo.pt
} 


\section{A Revisão do Código do Trabalho}

\section{RESUMO}

Neste working paper apresentamos uma reflexão sobre o actual processo de revisão da Lei do Trabalho em Portugal.

Num contexto socioeconómico especialmente complexo e, ao mesmo tempo, desafiante para Portugal, a revisão do Código do Trabalho - suportada pelo documento Reforma das Relações Laborais, apresentado em 22 de Abril de 2008 - apresenta como objectivo central "Promover um novo compromisso social, mais equitativo e mais favorável à competitividade das empresas, sobre a regulação dos sistemas de relações laborais, de protecção social e de emprego".

Assim, e uma vez que esta mudança legislativa propõe um conjunto de eixos de reforma assentes em vários diagnósticos sobre o mercado de trabalho português, procuraremos aqui reflectir sobre estas propostas.

\section{ABSTRACT}

In this working paper we present a theoretical reflection about the present Portuguese Labour Law revision.

Considering the complex and challenging economical and social context, the revision of the Portuguese Labour Law - supported by the Reforma das Relações Laborais document, presented on April $22^{\text {nd }} 2008$ - outlines as its main objective "To promote a new social compromise, more equitable and more favorable to enterprise competition, about the labour law regulation, social protection and employment”.

Thus, and once this legislative change proposes a set of reform axis based in several diagnostics about the Portuguese labour market, we aim to reflect about these proposals.

\section{O CONTEXTO SOCIOECONÓMICO DA REVISÃO}


A actual discussão em torno da revisão do Código do Trabalho - que adopta parte das teses da Comissão do Livro Branco das Relações Laborais (CLBRL) - apoia-se no documento Reforma das Relações Laborais, apresentado pelo Governo em 22 de Abril de 2008, e que traduz um conjunto de "Propostas para um novo consenso na regulação dos sistemas de relações laborais, de protecção social e de emprego”.

Numa altura em que assistimos a uma acentuada reconfiguração do modelo socioeconómico, a revisão da lei laboral deve merecer a máxima atenção.

Desde logo, este debate não pode ser desenquadrado de uma apreciação sobre os amplos propósitos de política social europeia.

Em 2006 - e em resposta àquilo que designou como os "Desafios do século XXI" - a Comissão Europeia apresentou, no denominado Livro Verde sobre a Modernização da Legislação do Trabalho, diversos objectivos e um desafio político ao mercado de trabalho europeu: o de "Modernizar o Direito do Trabalho" (Comissão das Comunidades Europeias, 2006).

Reconhecendo que a génese do Direito do Trabalho se fundou na necessidade de atenuar as desigualdades económicas e sociais inerentes à relação de trabalho, mas que "é desejável que o Direito do Trabalho evolua no seio dos Estados-membros”, a Comissão Europeia - assumindo-se como um catalisador de apoio à acção dos Estados e dos parceiros sociais, com vista a reforçar os objectivos da Estratégia de Lisboa - realça nesse documento a ideia de que a modernização do Direito do Trabalho constitui uma das principais condições para assegurar a adaptação de trabalhadores e de empresas aos desafios da globalização (idem) ${ }^{2}$.

E, fundamentalmente, este Livro Verde enfatiza a necessidade de fomentar um "quadro regulamentar mais reactivo”, defendendo, genericamente, que será conveniente que cada Estado-membro amplie as formas de flexibilizar a relação de trabalho, reforçando concomitantemente - a respectiva protecção social dos cidadãos ${ }^{3}$.

De facto, o debate sobre a "Modernização do Direito do Trabalho" vai muito além da estrita reflexão jurídica, convocando igualmente um enquadramento socioeconómico.

O mundo mudou muito na última década, e a União Europeia (UE) sujeita ao movimento da globalização - e, em especial, aos sucessivos alargamentos e, desde Janeiro de 2005, à livre concorrência internacional - tem vindo a assistir a fortes transformações no seu espaço socioeconómico.

\footnotetext{
${ }^{2}$ Assim - e reconhecendo que, desde os anos 1990, as reformas legislativas nos diferentes países da União se têm pautado pela flexibilidade ao nível da diversificação contratual - o Livro Verde europeu afirma ainda que a protecção das condições de trabalho e o esforço pela melhoria da qualidade do trabalho nos Estados-membros depende, essencialmente, da legislação nacional e da eficácia das medidas de controlo adoptadas em cada Estado (Comissão das Comunidades Europeias, 2006).

${ }^{3}$ Remetendo as propostas específicas para o reconhecimento e a adopção do entendimento de cada Estado-membro sobre a sua exequibilidade, após uma adequação ao contexto socio-económico de cada país.
} 
Desde logo, sabemos que a globalização potencia, como nunca antes se viu, um inédito contacto entre povos, pessoas, e empresas, tornando o mundo muito mais interdependente. Mas potencia igualmente a incerteza.

Particularmente inquietante é o movimento das deslocalizações - opções de estratégia empresarial que se evidenciam através de movimentos geográfico-empresariais que, muitas vezes implicando o encerramento prévio de empresas no país de origem, promovem a transferência da totalidade ou de parte da produção para o estrangeiro - que se decidem em função de factores de atracção como a dimensão do mercado, a remuneração e a qualificação da mão-de-obra, a qualidade dos fornecedores locais e as acessibilidades.

No plano económico, as economias europeias (exceptuando os casos dos países do alargamento europeu) apresentam taxas de crescimento muito modestas ${ }^{4}$ e, em consequência da sujeição a uma forte concorrência internacional, as sucessivas crises vividas no sector industrial - em especial na indústria têxtil, do calçado e automóvel - têm provocado quebras significativas e obrigado muitas empresas a reestruturar (no sentido do emagrecimento organizacional) ou a deslocalizar a sua produção para outros destinos mais atractivos, nomeadamente para a Ásia e os países do alargamento europeu, com consequências ao nível do emprego ${ }^{5}$.

No plano social, se é possível considerar a emergência de novos sectores de produção e, consequentemente, de novas oportunidades de emprego, importa não ignorar os fenómenos de sectores económicos que desaparecem, da consequente eliminação de empregos, e da emergência de “regiões (ou até mesmo países) em crise” (Rebelo, 2008).

Estas foram, aliás, as principais razões pelas quais a Estratégia de Lisboa - iniciativa definida em Março de 2000 e que se traduziu num compromisso de cooperação entre os Estados-membros da UE, tendo como principal objectivo fazer desta o "espaço económico mais competitivo do mundo até 2010” - foi revista em Março de 2005. Aí - e operado um balanço intercalar Estratégia de Lisboa - ficou patente que o desempenho esperado para a economia europeia (em matéria de crescimento, produtividade e emprego) não foi atingido. Foi então que a Comissão Europeia - no intuito de assegurar capacidade de a União enfrentar os desafios da

\footnotetext{
${ }^{4}$ Sendo as previsões da Comissão Europeia para o ano de 2008 de um crescimento de $2 \%$ e de apenas 1,7\% quer para a zona Euro quer para Portugal. É ainda expectável um crescimento de 1,8\% em 2009 para os países da União e de apenas 1,5\% para os países da zona euro (cfr. European Commission, 2008). De facto, os anos de 2008 e 2009 anunciam-se difíceis particularmente para a economia da zona euro: a força do euro pesará sobre as exportações à medida que - impulsionada pelos aumentos do preço do petróleo e dos bens alimentares - a inflação sobe, fazendo-se reflectir no consumo das famílias, sobretudo no caso das famílias com menor poder de compra, que integram trabalhadores com salários baixos ou membros do agregado familiar desempregados.

${ }^{5}$ De facto, com a expansão tecnológica e a liberalização da economia, assistimos a um nomadismo considerável sobretudo das empresas europeias e norte-americanas. Deste modo, nestes países a preocupação dos poderes públicos é, agora, a de resistir à deslocalização do emprego (sobretudo industrial, mas também agrícola, piscícola e terciário), procurando tornar atraente o mercado nacional de emprego. Razão pela qual nos países mais industrializados da União Europeia - em especial na Alemanha, França e Reino Unido - a preocupação com as deslocalizações tem sido central na agenda política. Por exemplo, nos EUA, em Outubro de 2004, foi aprovado pelo Congresso o American Jobs Creation Act, através do qual se propôs a redução de impostos às empresas industriais que produzam em território nacional (cfr. Rebelo, 2005b) e, em 2007 e 2008, na campanha eleitoral para as eleições presidenciais, tanto Barack Obama como Hillary Clinton advogaram medidas de salvaguarda e protecção ao emprego em resposta ao tema da livre concorrência internacional, pelo que a assunção destas posições poderá vir, a prazo, a reforçar esta tendência política nos EUA.
} 
globalização e da livre concorrência internacional - lançou um convite aos Estados-membros para apresentarem, anualmente, programas de reformas nacionais, através dos Planos de Acção Nacionais ${ }^{6}$.

Ora, Portugal - país periférico - enfrenta estes desafios sociais e económicos de forma ainda mais acentuada.

E, como já anteriormente defendemos, acautelando um difícil (mas necessário) "justo equilíbrio” é fundamental, no âmbito da definição da nova política laboral nacional, responder a quatro grandes desafios específicos, através de um indispensável diálogo social: aumentar a qualidade do emprego; facilitar a adaptação das empresas aos desafios da concorrência internacional; transformar o trabalho num factor de imunidade contra a pobreza; assegurar a sustentabilidade financeira do regime público de segurança social (Rebelo, 2008a).

Assim, é preciso que o Direito do Trabalho cumpra a sua função ao nível da definição das políticas de emprego e promova a realização específica, no domínio das relações laborais, de valores e de interesses reconhecidos como fundamentais para a sociedade portuguesa.

Desde a entrada em vigor do Código do Trabalho - Lei no 99/2003, de 27 de Agosto, que visou, maxime, sistematizar e flexibilizar a lei laboral portuguesa - assistiu-se a fortes transformações no seu espaço social e económico e o legislador não pode ignorar nem estas mudanças globais nem as especificidades do modelo socioeconómico nacional e dos actuais modelos de gestão de recursos humanos.

Também a actual revisão do Código do Trabalho (CT) deverá afirmar-se através da articulação entre a realização desses valores sociais inalienáveis e as novas exigências de gestão e competitividade das empresas. Daí que - e ainda que se reconheça que a lei laboral não é a única, nem a principal, condicionante do aumento da competitividade nacional ${ }^{7}$ - as alterações ao CT no sentido da "Modernização do Direito do Trabalho" não possam deixar de ser consideradas importantes para o desenvolvimento, a prazo, do país, na medida em que podem ter impactos significativos no emprego, no bem-estar social das pessoas, e na economia.

\section{OS GRANDES PROPÓSITOS DE REVISÃO LEGISLATIVA}

\footnotetext{
${ }^{6}$ De que o Plano Nacional de Acção para o Crescimento e Emprego - PNACE, para o período 2005/2008 foi exemplo. Através de um conjunto de cento e vinte e cinco medidas que procuraram responder à agenda de "modernização e crescimento do país em diversos domínios - nomeadamente, o crescimento, a competitividade o emprego e a coesão social", o PNACE foi aprovado em Outubro de 2005, procurando - embora com resultados ainda por escrutinar justamente concretizar a Estratégia de Lisboa em Portugal (Rebelo, $2006 \mathrm{c}$ ).

${ }^{7}$ Uma vez que um moderno e atractivo sistema fiscal assim como uma eficiente Administração Pública e um eficaz sistema de Justiça são, paralelamente, condições fundamentais para a atracção e manutenção de investimento e, consequentemente, de emprego em território nacional (também, parcialmente, neste sentido cfr. Comissão das Comunidades Europeias, 2006).
} 
Partindo da identificação de cinco problemas principais no mercado de trabalho em Portugal $^{8}$, o documento negocial de proposta de revisão do CT - intitulado Reforma das Relações Laborais e apresentado em 22 de Abril de 2008 - sugere quatro grandes propósitos orientadores da reforma legislativa: valorizar o diálogo social; tornar mais compreensível, eficaz e estável a lei; promover uma maior auto-regulação do mercado de trabalho, via contratação colectiva; e, por fim, alargar o objecto social da reforma, visando não apenas as leis laborais mas englobando também as políticas de segurança social, emprego e formação profissional e promovendo a sua articulação.

Igualmente expõe - por estas razões - cinco principais eixos que estruturam as medidas propostas: aumentar a adaptabilidade das empresas; promover a regulação contratual colectiva; alterar o regime dos despedimentos; reforçar a efectividade da legislação laboral; combater a precariedade e segmentação e promover a qualidade do emprego, adaptando de forma articulada a legislação laboral, proteç̧ão social e políticas de emprego.

Passaremos, pois, de seguida - e ainda que não seguindo a ordem de apresentação dos eixos propostos - a apresentar cada uma destas propostas, reflectindo, concomitantemente, sobre o seu conteúdo e prováveis impactos socioeconómicos e jurídicos em Portugal.

\subsection{COMBATER A PRECARIEDADE E PROMOVER A QUALIDADE DE EMPREGO}

Um dos grandes desafios da revisão do CT prende-se com o aumento da qualidade do emprego.

Com as actuais propostas para revisão da lei do Trabalho - e a par de um concomitante estímulo a medidas de flexibilidade qualitativa, promotoras de maior adaptabilidade - o Governo propõe um conjunto de medidas contra a precariedade laboral.

De facto, as tendências globais para o trabalho - reconhecidas em diversos estudos internacionais por nós já referenciados ${ }^{9}$ - há muito indicam que a precariedade integra um conjunto de relevantes transformações económico-sociais: os mercados de trabalho estão a tornar-se mais segmentados, sendo que estas mudanças têm profundas implicações ao nível social, acentuando desigualdades.

Contudo, e porquanto a precariedade laboral - sugerindo a ideia de trabalho transitório, instável, inseguro, ou seja, a ideia de alto risco ou elevada probabilidade de desemprego designa um fenómeno complexo, com contornos económicos, sociais e jurídicos, importa diferenciar realidades no seu conjunto multifacetado (Rebelo, 2004).

\footnotetext{
${ }^{8}$ Estes cinco problemas são: a reduzida adaptabilidade das empresas e trabalhadores; a debilidade e o escasso dinamismo da contratação colectiva; a rigidez formal do enquadramento legal; a escassa efectividade da lei e normas contratuais ou a elevada precariedade e segmentação do emprego.

9 Em Rebelo, G., 2004. De destacar, entre outros, os trabalhos de Belous, 1998, Gallie, et al, 1998, Barker and Christensen, 1998 e, ainda, Felstead and Jewson, 1999.
} 
Desde logo, a precariedade pode abranger, entre outras, ou a actividade por conta de outrem (de que os contratos a termo e os contratos de trabalho temporário são exemplo) ou as prestações de trabalho autónomo (independente); seja a precariedade legal (legitimadas por lei através das faculdades concedidas aos empregadores de, em situações temporárias, por exemplo, substituir um trabalhador ausente ou contratar para o exercício da actividade sazonal), seja a

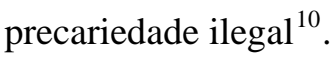

Por exemplo, de acordo com os dados do Eurostat, em 2005 Portugal era o terceiro país da UE, a seguir a Espanha e à Polónia, a apresentar a taxa de contratação emprego não permanente (incluindo-se aqui os contratos a termo e os contratos de trabalho temporário) mais elevada: 19,5\% (o que significa que um em cada cinco trabalhadores subordinados e por conta de outrem são contratados provisoriamente) face a uma taxa média europeia de 14,5\% (Eurostat, 2007: 131-146) ${ }^{11}$.

\subsubsection{CONTRATAÇÃO A TERMO E TRABALHO TEMPORÁRIO}

As propostas do documento governamental negocial passam por defender a diminuição do recurso ao trabalho a termo ${ }^{12}$ encorajando, por outro lado, o recurso à contratação sem termo, através do aumento da Taxa Social Única (TSU) a pagar pelas empresas que empregam pessoas a termo (para 26,75\% do salário ilíquido) e da diminuição da TSU relativa aos contratos de trabalho por tempo indeterminado (de 23,75\% para 22,75\%) ${ }^{13}$.

Mas aqui importará distinguir as situações de recurso legal à contratação provisória que possibilitam contratar a termo dentro dos ditames da lei e a que aludimos supra - das de abuso. Parece consensual que, em situações em que, por exemplo, exista uma necessidade verdadeiramente temporária de, sem se justificar o recurso a nova contratação, um empregador proceder à substituição de um trabalhador ausente ou contratar um trabalhador para o exercício da actividade sazonal não devem ser estas contratações penalizadas, elevando o custo social da

\footnotetext{
${ }^{10}$ Como oportunamente já caracterizámos em Rebelo, G. (2002), Emprego e Formas de Precariedade da Actividade Laboral - o caso de Portugal no contexto da UE, Tese de Doutoramento, Instituto Superior de Economia e Gestão, Universidade Técnica de Lisboa.

${ }^{11}$ Paralelamente não pode deixar de ser curioso notar que, na UE, os países que registam percentagens mais baixas de trabalho não permanente - Luxemburgo e Irlanda - têm sido países "líderes" em atracção de investimento directo estrangeiro (Chalmin, 2004).

${ }^{12}$ A procura de diminuir o recurso ao trabalho a termo - aumentando a TSU a pagar pelas empresas que empregam a termo e baixando a TSU relativa aos contratos de trabalho por tempo sem termo - procura desincentivar as empresas a recorrer de forma abusiva aos contratos a termo. Portugal tem hoje uma das mais altas taxas mais altas da União Europeia de trabalho provisório (incluindo-se aqui os contratos a termo e os contratos de trabalho temporário) e a segmentação do trabalho entre dois tipos de trabalhadores - uns que têm um grande grau de segurança e outros sem vínculo duradouro - é consensualmente reconhecida. Assim, a dúvida que permanece na actual revisão - até porque perante a proposta de agravamento da TSU para os contratos a termo é possível que exista transferência para contratação afim - é a de saber se também o regime jurídico do contrato de trabalho temporário acompanhará idênticas medidas de desincentivo.

${ }^{13} \mathrm{E}$, ainda, alterar a presunção legal de existência de um contrato de trabalho de modo a permitir o combate eficaz da Inspecção do Trabalho e do sistema judicial aos falsos recibos verdes; limitar a três anos a duração do contrato de trabalho a termo certo; criação um contrato de trabalho sem termo mas intermitente, que implica a prestação do trabalho apenas durante uma parte do ano mas mantém o vínculo laboral de contrato sem termo durante o resto do ano; interditar os estágios profissionais extra-curriculares não remunerados.
} 
contratação. De forma distinta, as situações verdadeiramente abusivas, isto é aquelas em que tendo a função preenchida carácter verdadeiramente duradouro, se contrate a termo, devem ser após fiscalização - devidamente penalizadas, em nome dos princípios da justiça ${ }^{14}$ e da lealdade de concorrência.

O Governo aponta ainda para a redução para metade da TSU a pagar pelas empresas que passem para os quadros os trabalhadores que estivessem a recibo verde ou os contratados a termo durante três anos e se se tratar de um jovem até 30 anos, a empresa ficará isenta do pagamento de contribuições, também durante três anos.

Além do mais, a duração máxima dos contratos a termo será de três anos, afastando a possibilidade de renovação prevista, actualmente, no no 2 do artigo $139^{\circ}$ do CT.

Na linha do que já defendemos anteriormente, importa reconhecer que a instabilidade laboral proporcionada por estas formas de contratação tende a repercutir-se, quer na performance das empresas, quer na vida pessoal e familiar dos trabalhadores (Rebelo, 2002b; Rebelo, 2004; Rebelo, 2008a).

Desde logo porque, sendo os períodos contratuais, por vezes, muito curtos, empregador e trabalhador não chegam a encetar um verdadeiro "compromisso laboral”, existindo, de ambos os lados, desconfiança relativamente ao futuro. O empregador, pautando-se por uma lógica a curto prazo, não investe na formação e no enriquecimento de competências do trabalhador, temendo que nunca venha a beneficiar delas. Por seu turno, o trabalhador, conhecedor da sua instabilidade profissional e da eventual mobilidade forçada daí decorrente, tende a pautar a sua colaboração numa perspectiva a curto prazo, desatento às necessidades da empresa, pouco participativo e envolvido com os objectivos da empresa, e sempre vigilante quanto à possibilidade de experimentar a sua mobilidade profissional. E esta desconfiança mútua é extremamente nociva para o desenvolvimento quer de competências organizacionais, quer de competências individuais, repercutindo-se na produtividade do trabalho ${ }^{15}$.

Assim, em Portugal urge sensibilizar a sociedade para a ideia de que importa valorizar de forma crescente - a importância do capital humano no desenvolvimento das organizações, em particular promovendo a captação (e a manutenção) dos melhores recursos humanos por via de vínculos contratuais estáveis e promotores da assunção de maior compromisso laboral.

\footnotetext{
${ }^{14}$ Seguindo o principio geral latente na ideia de justiça de que os indivíduos têm direito, uns em relação aos outros, a uma certa posição relativa de igualdade (Hart, 1961).

${ }^{15}$ Razão pela qual - como tive oportunidade de salientar em artigo de opinião publicado no Jornal de Negócios, que intitulei "Flexisegurança à espanhola" - em Espanha o Governo de Rodríguez Zapatero aprovou, em Julho de 2006, uma lei intitulada Para a Melhoria e o Crescimento do Emprego. Considerada como um passo essencial no impulso da actividade económica e na melhoria do emprego estável, esta lei procurou diminuir a precariedade laboral, oferecendo às empresas incentivos financeiros pela conversão dos contratos a termo em contratos por tempo indeterminado. E, no final de 2006, o balanço não podia ter sido mais positivo: só nesse ano celebraram-se mais de dois milhões de contratos permanentes o que, além de permitir inferir pela diminuição da precariedade, promoveu o crescimento do emprego (Rebelo, 2007a). Também em plena campanha presidencial francesa, em 2007, a segurança dos percursos profissionais foi um dos temas a alcançar consenso entre os candidatos. Confrontados com uma precariedade crescente entre os jovens, que se inserem no mercado de trabalho mediante contratos de trabalho não permanente, Ségolène Royal e Nicolas Sarkozy salientaram, por diversas vezes, a importância de "contrariar o aumento da precariedade".
} 
Acresce que o aumento da precariedade laboral - caracterizada genericamente pelo recurso a contratações provisórias e por percursos profissionais intermitentes - tende a repercutir-se, de forma gravosa quer no bem-estar dos trabalhadores e das suas famílias, com repercussões ao nível da sua saúde e ao nível social ${ }^{16}$ quer no sistema financeiro da Segurança Social, pois as situações de desemprego, ainda que não duradouras, significam perda de receitas para o sistema e, na maioria das vezes, aumento da despesa pública.

E, atendendo a que Portugal é um país marcadamente envelhecido, também aqui é preciso considerar um outro propósito da Modernização do Direito do Trabalho: o de assegurar, concomitantemente, a sustentabilidade financeira da Segurança Social.

Na medida em que um dos desafios que se coloca ao mercado de trabalho português é também o de reduzir a elevada percentagem de contratação subordinada provisória - vínculos de trabalho a termo e vínculos de trabalho temporário - e aprofundar a protecção social, a revisão do Código do Trabalho propõe novos incentivos à contratação por tempo indeterminado, designadamente reduzir um ponto percentual na taxa contributiva a cargo do empregador sobre todos os contratos sem termo (e, simultaneamente, um aumento de três pontos percentuais a cargo do empregador sobre os contratos a termo $)^{17}$.

\subsection{2. "FALSO TRABALHO INDEPENDENTE”}

A erradicação da precariedade ilegal - que não tem merecido suficiente atenção do poder político - através do combate ao recurso ao falso trabalho independente ou ao trabalho clandestino, há muito que se encontra identificada pela Inspecção-Geral do Trabalho (actual Autoridade para as Condições de Trabalho - ACT) como objecto central e regular de fiscalização.

\footnotetext{
${ }^{16}$ Por exemplo, no plano da saúde alguns trabalhos de investigação concluíram que os efeitos negativos para a saúde psíquica dos trabalhadores se demonstram de longa duração e afectam não só o trabalhador empregado como toda a sua família. Além do mais, as consequências do emprego precário projectam-se ao plano social, pois a par da incerteza remuneratória e da quebra de um estatuto profissional, a precariedade acarreta custos sociais elevados, nomeadamente o aumento do risco de exclusão social, o afastamento progressivo dos trabalhadores da formação profissional ou ainda em termos mais genéricos a dissimulação do desemprego real ou a deficiente sustentação do sistema de segurança social (cfr. com desenvolvimento Rebelo, 2002b e Rebelo, 2004).

${ }_{17}$ Trata-se de uma resposta que procura obviar ao aumento de um mercado excessivamente segmentado, e que foi, aliás, recentemente adoptada em diversos ordenamentos jurídicos, nomeadamente em Espanha e em França, onde se vem promovendo a contratação por tempo indeterminado.
} 
Contudo, a sua fiscalização tem-se mostrado difícil - assistindo-se mesmo a uma fraqueza crónica dos sistemas de fiscalização (Monteiro Fernandes, 2004) - dadas as permanentes dificuldades quer na identificação precisa deste tipo de contratação (que exige estreita articulação com o Ministério Público) quer na mobilização de recursos humanos.

De facto, em Portugal uma das especificidades do mercado de trabalho é a do traço relativamente constante e acentuado de trabalho independente, uma vez que o nosso país apresenta uma das percentagens mais significativas de trabalho independente da UE e mesmo da $\mathrm{OCDE}^{18}$.

Ou seja, na gestão das suas relações laborais, as empresas - incluindo aqui, paradoxalmente, o Estado - recorrem a esta forma de contratação, de forma directa (mediante o ajuste directo de recibos verdes) ou de forma indirecta (através de cadeia de empresas em subcontratação), com o duplo objectivo de contornarem os alegados "constrangimentos" impostos à actividade económica pela legislação do trabalho e de reduzirem os custos sociais do trabalho (Rebelo, 2003:6).

Ora, e porque estas formas de trabalho traduzem uma grande desprotecção jurídica pois estes independentes, estando na realidade, totalmente dependentes, jurídica e economicamente, encontram-se subtraídos à tutela do Direito do Trabalho - convém contrariar esta “cultura do incumprimento" e de “dissimulação do paradigma laboral” (Monteiro Fernandes, 2004: 21) instalada na sociedade portuguesa, concebendo novas metodologias de fiscalização com o objectivo de sustentar uma efectiva acção continuada capaz de mudar mentalidades e de influenciar novas práticas de gestão.

E, neste ponto, será decisivo articular o propósito de erradicação da precariedade ilegal com o disposto no Eixo 4 das propostas para a Reforma das Relações Laborais, subordinado ao título "Reforçar a efectividade da legislação laboral". Desde logo, porque é evidente a necessidade de, designadamente, melhorar os mecanismos de participação ao Ministério Público dos factos que constituam ou possam constituir crime pela ACT; criar um registo público de infracções laborais de natureza contra-ordenacional e criminal; estabelecer mecanismos dissuasores do incumprimento de pagamento tempestivo das coimas aplicáveis a infracções laborais, através de instrumentos que permitam uma maior efectividade no sistema de contraordenações; e reforçar o quadro de sanções acessórias em caso de reincidência em contraordenação mais grave.

Além do mais - e seguindo as propostas contidas no Livro Branco das Relações Laborais (CLBRL, 2007: 91) - importa que, entre outras, sejam criadas condições para que a Autoridade para as Condições de Trabalho seja dotada de recursos - humanos, técnicos,

\footnotetext{
${ }^{18}$ Por exemplo, e como já salientámos anteriormente (cfr. Rebelo, 2003 e, ainda, seguindo a nossa posição, Eurofound, 2005), de acordo com o Eurostat, em 2001 enquanto para a média dos quinze países da UE o trabalho independente se situava nos $14,0 \%$, em Portugal situava-se nos $25 \%$ sendo o segundo país, logo a seguir à Grécia a registar a mais alta percentagem de trabalho independente (Eurostat, 2002: 88-89).
} 
materiais e financeiros - adequados ao desenvolvimento eficaz da sua actividade e que, juntamente com o Ministério Público, disponha da consagração legal de meios de acção nas suas áreas de competência.

Daí que, receando que a proposta de obrigar as empresas a pagar parte das contribuições para a Segurança Social dos trabalhadores que colaboram com a empresa mediante contratos de prestações de serviço (emitindo o respectivo recibo verde) possa vir a legitimar o recurso ao "falso trabalho independente" se não se fizer acompanhar por um inequívoco reforço de meios de fiscalização e punição, interessará realçar que a erradicação do "falso trabalho independente" o papel central cabe, e caberá, à Autoridade para as Condições de Trabalho ${ }^{19}$.

\subsection{IMPULSIONAR A ADAPTABILIDADE DAS EMPRESAS}

Um segundo desafio que se coloca ao mercado de trabalho passa - como já o advogámos anteriormente (Rebelo, 2006b) - por encontrar um novo compromisso social, que permita conciliar os direitos de cidadania dos trabalhadores com o aumento da capacidade de adaptação das empresas aos desafios da competitividade.

Parece-nos imprescindível que - observando as regras de respeito e salvaguarda dos princípios e valores específicos constitucionalmente e legalmente consagrados - os conjuntos normativos de Direito do Trabalho (legais ou convencionais) se adaptem às evoluções do mercado de trabalho, induzidas por mudanças de natureza diversa.

Hodiernamente, a capacidade de adaptação contínua das empresas condiciona a sua sobrevivência e as organizações são tanto mais flexíveis quanto apresentam um grande número de configurações potenciais, permitindo escolher rapidamente - e economicamente - qual destas configurações se adapta melhor à envolvente. A empresa flexível é aquela que dispõe de sobrecapacidades (ligadas aos produtos, aos processos mas também à organização e às pessoas) para fazer face a um imprevisto (Rebelo, 2002: 84-85).

Em particular, é necessário enriquecer as temáticas relacionadas com as formas de flexibilidade interna - importante instrumento de Gestão de Recursos Humanos que terá, se bem compreendido, consequências muito positivas no espaço laboral português - em especial, com a flexibilização da dimensão temporal do trabalho.

Os parâmetros a que obedece a determinação quantitativa da prestação de trabalho, isto é, a delimitação do tempo de trabalho a que cada trabalhador está adstrito, assume importante

\footnotetext{
${ }^{19}$ De realçar que, a proposta constante do documento Reforma das Relações Laborais indica que os descontos para a Segurança Social dos trabalhadores independentes deixarão de ser feitos mediante uma percentagem fixa dos Indexantes de Apoios Sociais e passarão a variar de acordo com o rendimento obtido. Ou seja, a taxa de $24,6 \%$ sobre o rendimento - que será equivalente a $70 \%$ do valor dos recibos passados - será única para os trabalhadores independentes, acabando assim os dois regimes actuais. Já as empresas serão chamadas a pagar $5 \%$. Ainda assim, não podemos deixar de realçar sérias dúvidas quanto à proposta de obrigar as empresas a pagar parte das contribuições para a Segurança Social dos trabalhadores que colaboram com a empresa mediante contratos de prestações de serviço (emitindo o respectivo recibo verde). Como sempre o defendemos na erradicação do "falso trabalho independente" o papel central cabe, maxime, à Autoridade para as Condições de Trabalho (Rebelo, 2003).
} 
significado económico. Desde 1996 que o legislador vem acentuando as condições de adaptabilidade na organização dos tempos de trabalho, introduzindo maior flexibilidade ${ }^{20}$. Mas, dentro de limites legais, convém reforçar a adaptabilidade fundada em instrumento de regulamentação colectiva de trabalho e, ainda, a adaptabilidade assente na celebração de acordos entre o empregador e os trabalhadores individualmente considerados.

As propostas do Governo nesta área (integradas no Eixo 1 "Aumentar a adaptabilidade das empresas”) visam, desde logo, permitir que as convenções colectivas regulem a possibilidade de fixação dum número anual de horas de trabalho a aplicar em conjunto com os limites de variação diária e semanal do tempo de trabalho ${ }^{21}$ e da garantia de repouso com eles compatíveis ("banco de horas”"22); admitir a existência de horários de trabalho com modulação da duração diária e semanal do tempo de trabalho por períodos inferiores a um ano e, ainda, a existência de horários que concentram a prestação diária do tempo de trabalho em determinados dias da semana e aumentem o número de dias de repouso semanal (“horários concentrados”). Além do mais, propõe-se a criação da adaptabilidade grupal dentro das empresas; formas de compensação monetária ou em tempo de descanso compensatório do trabalho suplementar e o desconto monetário do absentismo não remunerado ou a sua compensação em tempo de trabalho, nomeadamente a criação de períodos de licença e de férias não previstos na lei ${ }^{23}$.

Trata-se pois de um instrumento que - conferindo maior protagonismo à contratação colectiva assegura, simultaneamente, direitos de cidadania aos trabalhadores - responde aos reptos económicos actuais, podendo facultar um essencial aumento da capacidade de adaptação das empresas aos desafios da competitividade internacional ${ }^{24}$.

Menos consensual será, no plano das relações individuais de trabalho, a implementação do conjunto destas medidas de adaptabilidade.

\footnotetext{
${ }^{20}$ Designadamente através da Lei $n^{\circ} 21 / 96$, de 23 de Julho, da Lei $n^{\circ} 73 / 98$, de 10 de Novembro (que transpôs a Directiva $n^{\circ}$ 93/104/CE, do Conselho) e, posteriormente, do Código do Trabalho, Lei $n^{\circ}$ 29/2003, de 27 de Agosto, que se manteve na linha destas leis.

${ }^{21}$ Reforçando a capacidade de adaptação das empresas a um movimento de transformação da economia que é muito forte, que se faz sentir em particular nas zonas mais expostas à concorrência internacional através da modulação dos horários - medida já prevista no Código do Trabalho (Lei no 99/2003, de 27-8) - num período de quatro meses até um ano.

${ }_{22} \mathrm{O}$ "banco de horas" e a possibilidade de negociar, individualmente, com os trabalhadores a gestão do tempo de trabalho está, constitucionalmente, condicionada ao direito a um limite máximo da jornada de trabalho e, ainda, à fixação, a nível nacional, dos limites da duração do trabalho (cfr. al. d do $n^{\circ} 1$ do art. $59^{\circ} \mathrm{CRP}$ e da al. b do $n^{\circ} 2$ do mesmo artigo). Esta figura do "banco de horas" tem sido recentemente usada noutros ordenamentos jurídicos como, por exemplo, na Alemanha onde a elevada dinâmica de acordos sectoriais e de empresa sobre revisão das durações dos períodos normais de trabalho e sobre trabalho suplementar têm sido, desde 2003 até à data, determinantes para a salvaguarda de emprego e a diminuição da taxa de desemprego.

${ }^{23}$ Mas a dúvida que persiste é a de saber se se mantém, ou não, a não inclusão neste grupo "da duração mínima do trabalho nocturno", tal como está actualmente prevista no Código do Trabalho (i.e., sete horas diárias).

${ }^{24}$ De facto no documento Reforma das Relações Laborais - que acolhe, na generalidade, as recomendações do Livro Branco sobre as formas de flexibilidade interna - propõe-se que se mantenham no Código do Trabalho as normas em vigor sobre a definição do tempo de trabalho, os limites dos períodos normais de trabalho diário e semanal, a duração mínima dos períodos de repouso intercalar (diário, semanal e anual) e a duração máxima do trabalho dos trabalhadores nocturnos, devendo manter-se ainda as normas sobre os limites do trabalho suplementar, a previsão da isenção de horário de trabalho, a definição dos modelos de adaptabilidade do horário de trabalho e a adaptabilidade individual do tempo de trabalho. Em contrapartida, defende-se que sejam suprimidas do Código do Trabalho as normas sobre efeitos da redução dos limites máximos dos períodos normais de trabalho e sobre o critério quantitativo de delimitação do trabalho a tempo parcial.
} 
Como se sabe, a prestação de trabalho subordinado pode estar na origem de relações individuais de trabalho, em que estão em jogo interesses meramente individuais e, ainda, de relações colectivas de trabalho, em que estão em causa interesses colectivos ou de ramo de actividade económica. Desde logo, porque o reconhecimento da autonomia colectiva "tende a reconduzir o contrato de individual” a um papel restrito "dado que, entre os sujeitos colectivos (...) não existem relações de subordinação ou dependência”. Assim, sendo desejável que se promova a negociação desta adaptabilidade no plano das relações colectivas, já parece pouco defensável ao nível das relações individuais de trabalho.

De facto - e acompanhamos Monteiro Fernandes - maxime nas relações individuais de trabalho, o padrão de referência do Direito do Trabalho "é marcado pela desigualdade originária dos sujeitos, ou seja, pela diferença de oportunidades e de capacidades (...) daí que a finalidade “compensadora” seja assumida como um pressuposto da intervenção normativa” (Monteiro Fernandes, 2004: 26). Desta forma - e se no âmbito da contratação colectiva, a flexibilidade da gestão do tempo de trabalho deve ser considerada um importante instrumento de adaptabilidade empresarial - permitir tal possibilidade no plano individual acentuaria a já de si desequilibrada relação individual de trabalho.

Já no que respeita ao despedimento por inadaptação a proposta - constante da redacção do Livro Branco (CLBRL, 2007: 112-113) - é a de alargar o instituto, ditando que passe a estar igualmente associado a "alterações na estrutura funcional do posto de trabalho".

Em Portugal - por força do disposto no artigo $53^{\circ}$ da Constituição da República Portuguesa - há muito que a invocação de “justa causa” é uma condição de validade do despedimento na ordem jurídica portuguesa ${ }^{25}$.

Não obstante, o debate sobre os limites desta noção de "justa causa” - conceito que a própria Constituição não determina - tem vindo a ser, periodicamente, promovido. Por exemplo, no Acórdão nº 107/88 do Tribunal Constitucional discutiu-se o alargamento do conceito de "justa causa” a uma figura próxima, mas distinta, da inadaptação: a "inaptidão" do trabalhador. E, relativamente a este conceito, o Tribunal Constitucional pronunciou-se, por maioria, no sentido da sua inconstitucionalidade, atendendo à circunstância de a Constituição ter suprimido como causa de despedimento o "motivo especial atendível”, disposto no Decreto-Lei $n^{0} 372-A / 75$, de 16/07 (diploma que definiu justa causa).

Contudo, a reforma laboral de 1989 - concretizada pelo Decreto-Lei n ${ }^{\circ}$ 64-A/89, de 27/02 - operou uma marcante inovação ao nível da cessação do contrato de trabalho em Portugal: ao alargar o despedimento à extinção de posto de trabalho, a “justa causa objectiva”,

\footnotetext{
${ }^{25}$ Contudo nas primeiras leis sobre a cessação do contrato de trabalho que remontam a 1937 , seguindo-se o $\mathrm{DL} \mathrm{n}^{\circ} 47$ 032, de 27/05/1966 e o DL nº 49 408, de 24/11/1969, o traço mais significativo era a consagração de um regime de liberdade de despedimento, no sentido em que eram admitidos os despedimentos não motivados ou também designados despedimentos ad nutum, embora o empregador estivesse sujeito à obrigação de fazer anteceder o despedimento de um aviso prévio de duração variável e no pagamento de indemnizações. Sobre esta evolução histórica cfr. Rebelo, 1999: 117-122.
} 
alheia ao exercício do poder disciplinar, foi adquirida na lei portuguesa, mantendo-se até hoje no Código do Trabalho.

Mas este movimento de flexibilização da cessação do contrato de trabalho foi ainda reforçado com a aprovação do Decreto-Lei $n^{\circ}$ 400/91, de 16/10, relativo ao despedimento por inadaptação do trabalhador às modificações tecnológicas introduzidas no posto de trabalho.

Na sequência do Acordo Económico e Social de Outubro de 1990, o despedimento por inadaptação foi, à altura, aceite pelos parceiros sociais na medida em que propiciava, às empresas, a possibilidade de responderem em contexto de modernização das suas estruturas, com maior adaptabilidade, à introdução de novas tecnologias, novos processos de fabrico e comercialização e, aos trabalhadores envolvidos nestes processos, o acesso a uma indispensável formação profissional e a um período de adaptação a essa formação, realçando - com uma centralidade inédita - a importância da formação profissional para a competitividade do país.

Acerca do Decreto-Lei n ${ }^{\circ}$ 400/91, de 16/10 pronunciou-se o Tribunal Constitucional Acórdão n ${ }^{0}$ 64/91 - no sentido da sua constitucionalidade. Os argumentos realçavam, por um lado, o facto de a "justa causa" ser igualmente susceptível de "cobrir factos ou situações objectivas” não se limitando à noção de justa causa disciplinar e, por outro, a ideia de a proibição constitucional dos despedimentos sem justa causa pretender apenas atingir os despedimentos arbitrários, ou seja, sem motivo justificado.

Em suma, a inadaptação está alicerçada na ideia de binómio posto de trabalho/trabalhador concreto, sendo necessário que tenha havido uma modificação recente no posto de trabalho resultante de novos processos de fabrico, de novas tecnologias ou de novos equipamentos e, por outro lado, uma inadaptação do trabalhador a esse posto de trabalho.

Assim, e perante uma eventual reconfiguração do conceito de inadaptação, parece-nos fundamental que se assegurem não só as actuais garantias do trabalhador consagradas no $\mathrm{n}^{\circ} 1$ do art. $407^{\circ}$ do Código do Trabalho - que são, afinal, a ratio essendi deste instituto - mas também que, em nome do princípio da segurança jurídica e em contexto de possível agudização dos problemas socioeconómicos, se acautelem subjectivismos que poderão ter, a prazo, um impacto não negligenciável no - já de si muito frágil - tecido social português.

\subsection{Promover a REgulaÇÃo CONTRATUAL COLECTIVA}

Em Portugal, e embora esse tenha sido um dos objectivos centrais do Código do Trabalho, a principal expressão da autonomia dos parceiros sociais, a contratação colectiva, encontra-se por dinamizar ${ }^{26}$. Paradoxalmente, o que se verificou é que o Código do Trabalho

\footnotetext{
${ }^{26}$ E, pelo menos em parte, as situações de impasse na contratação colectiva resultam de um débil diálogo social e de posições extremadas quer de empregadores (por exemplo, aproveitando-se do mecanismo da caducidade das convenções, forçarem a situações de vazio contratual e, em consequência, à negociação individual das condições de
} 
não resolveu a crise da contratação colectiva existente à data da sua entrada em vigor. De facto, de 2003 a 2005 o número de convenções outorgadas e de trabalhadores abrangidos pela contratação colectiva diminuiu, voltando apenas a sofrer novo impulso em 2006 - muito provavelmente devido à Lei $n^{0}$ 9/2006, de 20 de Março, que procedeu à revisão parcial do Código do Trabalho - mas ainda aquém de níveis atingidos, por exemplo, em 2000 (INE, 2007) ${ }^{27}$.

Por outro lado, esboça-se igualmente uma tendência para acentuar os traços da individualização das relações laborais, o que se traduz no modo de determinação dos principais aspectos das condições de trabalho, ou seja, do salário, do horário e da categoria profissional (CLBRL, 2007: 85).

Ora - e uma vez que um pouco por toda a Europa, a contratação colectiva tem-se revelado um importante meio de mudança socioeconómica, condicionando, nomeadamente, o ambiente de trabalho e a satisfação do interesse colectivo ${ }^{28}$ - importa contrariar estas tendências.

Assim, no plano colectivo, esta defesa dos interesses objectivos que se expressa pelo poder - reconhecido por lei - de por acordo, se conceberem "normas destinadas aos seus membros e que correspondem ao ponto de equilíbrio (...) dos interesses contrapostos” (Monteiro Fernandes, 2004: 647) - socioprofissionais dos trabalhadores e económicoempresariais dos empregadores - de que os mesmos são portadores”, estabelecendo a regulação das condições de trabalho no âmbito colectivo, designa a importância das relações colectivas de trabalho 29 .

No que respeita a tendências da contratação colectiva em geral, podemos observar que esta tem sido, em diversos países, um significativo meio de mudança socioeconómica (nomeadamente ao nível da formação profissional, da mobilidade e/ou da organização do trabalho) sendo que "o pressuposto basilar destes processos de revisão assenta na ideia de que as organizações são, de facto, evolutivas” (Almeida e Rebelo, 2004: 266).

Ora esta necessidade permanente de gestão da mudança deve repousar na ideia de criação de um forte compromisso sócio-laboral entre o empregador/empresa e os seus trabalhadores, o que implica repensar a própria relação colectiva de trabalho. Em nosso entender

trabalho) quer de alguns sindicatos que tendem a preferir o imobilismo encarando, de forma apriorista, as revisões como uma violação dos "direitos adquiridos" pelos trabalhadores.

27 De facto, de acordo com os dados do INE, e por categorias de convenções colectivas, em 2000, 2005 e 2006 celebraram-se, respectivamente: 245,151 e 153 contratos colectivos de trabalho; 22,28 e 26 acordos colectivos de trabalho; 103, 73 e 65 acordos de empresa (INE, 2007).

${ }^{28}$ No âmbito do Direito do Trabalho internacional podemos distinguir dois grandes modelos de sistemas nacionais de relações colectivas de trabalho: o modelo de negociação dinâmica ou institucional e o modelo de negociação estática ou contratual. Este último (o modelo português) assenta na concepção de que os processos negociais se identificam por um resultado (a convenção colectiva) "cristalizando-se" as condições de trabalho convencionadas por um certo período de tempo (Almeida e Rebelo, 2004: 263-265).

29 Por vezes também, denominadas por Relações Industriais (Pinto, 1996: 219). Para nós, esta designação tornou-se anacrónica com a emergência, a partir dos anos 1970, e a consequente expansão a partir dos anos 1980 e 1990 , do sector do comércio e serviços. Assistimos, gradualmente, a um processo de desindustrialização da actividade económica e a um acentuar da servicialização da mesma (Almeida, 2004: 96-98), pelo que defendemos que a expressão que, na actualidade, melhor abrange este conteúdo é precisamente "relações colectivas de trabalho". 
esta deve ser suportada pelo carácter negocial das convenções colectivas de trabalho, permitindo aos parceiros sociais - empregadores e trabalhadores ${ }^{30}$ - do sector ou subsector de actividade económica ajustar os conteúdos de regulação (normativa e obrigacional) desses IRCT às previsíveis situações de mudança organizacional que possam ocorrer (Rebelo, 2002: 20-23) ${ }^{31}$.

E precisamente porque partilhamos a ideia de que uma das "pedras de toque para uma evolução mais flexível do Direito do Trabalho é a negociação colectiva” (Palma Ramalho, 2003: 28) advogamos que deve ser, por isso, dinamizada (Almeida e Rebelo, 2004: 269).

O Eixo 2 das propostas de revisão do Código contempla a "Promoção da Regulação Contratual Colectiva”.

Assim, dois enunciados do documento Reforma das Relações Laborais, são: acolher as propostas de alteração dos artigos $4^{\circ}$ e $531^{\circ}$ do Código do Trabalho - respeitantes à articulação entre a lei, a contratação colectiva de trabalho e aos contratos individuais de trabalho; e promover a negociação de um acordo tripartido em sede concertação social sobre os critérios gerais, abstractos e permanentes de maior representatividade patronal e sindical e sobre os efeitos da maior representatividade no dever de resposta da contraparte a propostas de negociação colectiva, bem como sobre a possibilidade de extensão erga omnes das convenções colectivas de trabalho (nos termos do definido na CLBRL, 2007).

Em Portugal - mesmo considerando o propósito central de revitalização da contratação colectiva consignado na Lei ${ }^{\circ}$ 99/2003, de 27 de Agosto e a introdução de duas novidades relativamente ao disposto no Decreto-Lei n n 519-C1/79, de 29 de Dezembro, i.e., a alteração do princípio do tratamento mais favorável (artigo $4^{\circ}$ ) e a introdução do regime da caducidade e da sobrevigência das convenções colectivas de trabalho (artigo $\left.557^{\circ}\right)^{32}$ - a contratação colectiva, ou seja a principal expressão da autonomia dos parceiros sociais, carece de revitalização ${ }^{33}$.

A verdade é que, durante anos, diversas convenções colectivas - algumas outorgadas nas décadas de 1980 e de 1990 - se viram bloqueadas ou, em muitos casos, a negociação colectiva restringida a matérias de expressão pecuniária.

Ora, e após as alterações operadas pela Lei no 9/2006 de 20 de Março, o documento Reforma das Relações Laborais propõe agora alterar o regime da caducidade e da sobrevigência das convenções colectivas de trabalho ${ }^{34}$. A par, sugere ainda quer a criação da possibilidade

\footnotetext{
30 Representados quer por associações sindicais de grau inferior, quer por confederações sindicais, ou seja, organizações de cúpula que reúnem as associações sindicais de grau inferior (a Confederação Geral dos Trabalhadores Portugueses - Intersindical Nacional e a União Geral de Trabalhadores).

31 Importando mesmo para o texto legal exemplos de "boas práticas" que estejam já consagradas em negociação colectiva.

${ }^{32}$ Cujo mecanismo parece ter sido o de facilitar a negociação e pôr fim ao impasse que se verificava na contratação colectiva, alargando, por esta via, o campo possível da contratação colectiva.

${ }^{33}$ Tendo também o número de trabalhadores envolvidos diminuído significativamente. Contudo, em 2007 já se verificou uma evolução positiva, elevando-se o número de trabalhadores cobertos por convenções colectivas desde a entrada em vigor do Código do Trabalho.

${ }^{34}$ Mantendo-o como um regime predominantemente supletivo; simplificando-o; limitando a sobrevigência a 18 meses e a caducidade a 10 anos, contados a partir da entrada em vigor do primeiro texto que estabeleceu a renovação automática, o período de validade das normas contratuais sobre renovação sucessiva das convenções não revistas, prazo a partir do qual será aplicado o regime legal de sobrevigência e caducidade (MTSS, 2008: 4).
} 
legal de, nas empresas com 50 e mais trabalhadores - e procurando desbloquear a negociação -, os sindicatos delegarem os poderes de negociação em estruturas de representação colectiva ${ }^{35}$ quer a criação de um mecanismo de "arbitragem necessária”, accionável a pedido de uma das partes e quando não tenha sido concluída uma convenção colectiva nos doze meses subsequentes à verificação da caducidade (MTSS, 2008: 4).

Em particular, esta defesa da criação de uma figura de "arbitragem necessária” - caso as arbitragens voluntária e a obrigatória não quebrem o impasse negocial ao fim de um ano de convenção caducada - introduz um mecanismo apto a quebrar nefastos impasses na contratação colectiva $^{36}$.

Contudo, e considerando que o Acórdão do Tribunal Constitucional n. ${ }^{\circ}$ 306/2003, de 25 de Junho, entendeu que a caducidade da eficácia normativa da convenção não impede que os efeitos desse regime se mantenham quanto aos contratos individuais de trabalho celebrados na sua vigência e respectivas renovações - ou seja que quando a eficácia normativa da convenção colectiva caduque, o respectivo regime continua a aplicar-se aos contratos individuais de trabalho anteriormente celebrados e às respectivas renovações - será preciso acautelar que a arbitragem necessária não evite o vazio contratual durante um ano.

\subsection{RACIONALIZAR OS PROCESSOS DE DESPEDIMENTO}

No eixo 3 do conjunto das propostas intitulado "Redefinir as Regras de Procedimento”, o Governo prevê - dentro dos limites constitucionais da segurança no emprego e da proibição constitucional do despedimento sem justa causa - redefinir as regras inerentes ao processo de despedimento articulando-as com novas regras.

Esse conjunto de novas regras relativas à acção de impugnação do despedimento, possíveis mediante alteração do Código do Processo de Trabalho, passam pela determinação de que a prova da licitude do despedimento seja realizada em audiência de julgamento e que os tribunais se pronunciem sempre sobre a verificação e procedência dos fundamentos invocados para o despedimento (de acordo com a proposta da CLBRL).

Ao considerar necessário adoptar soluções legislativas que promovam a simplificação da carga processual, assume-se que o procedimento é um mero iter para assegurar que o trabalhador não seja despedido sem conhecer as razões em que se fundamenta a decisão de extinguir o vínculo.

Além do mais, propõe que em despedimentos que sejam apenas formalmente ilícitos, desde que tenham sido cumpridas as exigências de audiência prévia do trabalhador e de comunicação escrita da decisão fundamentada, se passe a permitir que - quando se prove em

\footnotetext{
${ }^{35}$ Neste aspecto - em nome do princípio da gestão democrática - seria conveniente que nas empresas com mais de 500 trabalhadores, os sindicatos pudessem delegar por votação.

${ }^{36} \mathrm{E}$ a verdade é que a procura de dinamizar a contratação colectiva, através de uma elaboração de lista de árbitros pelos representantes das associações sindicais e patronais com assento na Comissão Permanente de Concertação Social era já um propósito da Lei no 99/2003, de 27 de Agosto.
} 
tribunal o mérito da justa causa - se mantenha o dever do empregador de indemnizar o trabalhador, mas deixe de existir o dever de reintegração ${ }^{37}$.

Aqui, como se realça no Livro Branco das Relações Laborais, as garantias do trabalhador não parecem prejudicadas pois "estamos perante um procedimento interno da empresa que, em caso de impugnação do despedimento, não dispensa o empregador de demonstrar em juízo os factos de que decorre a justa causa invocada para fundamentar a cessação” (CLBRL, 2007: 109).

Por fim, quanto à proposta de "fazer o Estado suportar o custo dos salários intercalares quando a acção judicial se prolongar por mais de um ano”,38 - que encontra paralelo em países como a Espanha - a dúvida que existirá (muito embora a experiência espanhola o negue) será a de saber se isso significará mais um acréscimo de custos previsíveis para o Estado, considerando o já sobrecarregado Sistema de Segurança Social português (cfr. Rebelo, 2005a: 81-92).

\section{CONSIDERAÇõES FINAIS}

Parece consensual considerar que a presente revisão do Código do Trabalho - suportada pelo documento Reforma das Relações Laborais, apresentado em 22 de Abril de 2008 - ao procurar promover no domínio laboral "um novo consenso na regulação dos sistemas de relações laborais, de protecção social e de emprego", se insere num contexto europeu de incentivo à "Modernização do Direito do Trabalho".

Nesta mudança legislativa parece de salientar o propósito central de assegurar, simultaneamente, a adaptação de trabalhadores e de empresas aos desafios da globalização e da competitividade económica.

Uma vez que a generalidade das mutações económicas e sociais se repercutem no Direito do Trabalho, os debates que envolvem a actual revisão passarão, naturalmente, por discutir os desafios que o país enfrenta no que se concerne à globalização e à competitividade económica, em particular a capacidade de adaptação das empresas a estes grandes reptos.

Mas, necessariamente, ao legislador do Trabalho pede-se mais do isso. É preciso não perder de vista a realidade socioeconómica nacional. E, dado que a determinação das condições por que hão-de pautar-se, por exemplo, as relações individuais de trabalho é, na realidade, dominada por quem a oferece (os empregadores ou o empregador), ao legislador cabe -

\footnotetext{
${ }^{37}$ Dever consagrado como efeito geral da declaração de ilicitude do despedimento - na alínea b do $n^{\circ} 1$ do artigo $436^{\circ}$ da Lei no 99/2003, de 27 de Agosto - e que foi, recorde-se, parcialmente excepcionado aquando da elaboração do Código do Trabalho em 2003, através da possibilidade de, em caso de microempresa, o empregador se opor à reintegração do trabalhador despedido alegando que o seu regresso é "gravemente prejudicial e perturbador para a empresa" (cfr. $\mathrm{n}^{\circ} 2$ do artigo $438^{\circ} \mathrm{CT}$ ).

${ }^{38} \mathrm{E}$ que retoma parcialmente a proposta já firmada no Acordo de Concertação Estratégica de 1996 onde se lia "8.4. Análise da possibilidade de pagamento pelo Estado das remunerações vincendas superiores a seis meses por despedimento ilícito, quando se verifiquem demoras no processo superiores a esse prazo, por motivo não imputável ao empregador" (Conselho Económico e Social, 1996:101).
} 
assumindo essa missão como um pressuposto de intervenção normativa - salvaguardar a ordem social no domínio das relações económicas.

Assim, partindo do desígnio central desta revisão, afiguram-se particularmente positivas as mudanças propostas através da adopção de um conjunto de medidas de flexibilidade interna, maxime, da adaptabilidade do tempo de trabalho e de mobilidade profissional.

E se as medidas de flexibilidade qualitativa interna propostas - incidindo sobretudo na mobilidade interna dos trabalhadores, ou seja na extensão das suas qualificações e competências - permitem, de uma forma geral, que os trabalhadores e as empresas desenvolvam, respectivamente, importantes competências individuais e organizacionais, as medidas de flexibilidade quantitativa interna permitem, através das diversas formas de flexibilização do tempo de trabalho, aumentar a adaptabilidade das empresas.

Paralelamente a este desígnio central, o intento de combater a precariedade e de promover a qualidade do emprego, a ideia de prosseguir a revitalização da regulação contratual colectiva e, por fim, a proposta de racionalizar os processos de despedimento apresentam-se em geral como propostas positivas, muito embora persistam as dúvidas aqui supra expressas.

Por exemplo, no que se refere à diminuição da precariedade e à promoção da qualidade do emprego, importa que, entre outras, sejam criadas condições para que a ACT seja dotada de recursos - humanos, técnicos, materiais e financeiros - adequados ao desenvolvimento eficaz da sua actividade. De facto, se a actual proposta de obrigar as empresas a pagar parte das contribuições para a Segurança Social dos trabalhadores vinculados mediante contratos de prestações de serviço não se fizer acompanhar por um inequívoco reforço de meios de fiscalização e punição capazes de erradicar o “falso trabalho independente”, esta medida poderá, a prazo, gerar efeitos certamente não pretendidos pelo legislador.

Depois, e no que se refere à revitalização da regulação contratual colectiva, acompanhamos as propostas do documento Reforma das Relações Laborais, atendendo à necessidade premente de repensar a própria relação colectiva de trabalho. Em nosso entender esta deve ser suportada pelo carácter negocial das convenções colectivas de trabalho, permitindo aos parceiros sociais ajustar os conteúdos de regulação normativa e obrigacional das convenções colectivas de trabalho às situações de mudança organizacional que possam ocorrer no espaço socioeconómico português. Especialmente positiva afigura-se a criação da "arbitragem necessária” enquanto mecanismo apto a quebrar nefastos impasses na contratação colectiva.

Consideramos ainda que a ideia de redefinir as regras inerentes ao processo de despedimento articulando-as com novas regras, em especial a proposta de - em despedimentos que sejam apenas formalmente ilícitos e em que tenham sido cumpridas as exigências de audiência prévia do trabalhador e de comunicação escrita da decisão fundamentada - se permitir que se mantenha o dever do empregador de indemnizar o trabalhador, deixando de existir o dever de reintegração não parece colidir com os interesses fundamentais do trabalhador, uma 
vez que, em caso de impugnação do despedimento, não dispensa o empregador de demonstrar em juízo os factos de que decorre a justa causa invocada para fundamentar a cessação.

Por fim, a proposta de fazer o Estado suportar o custo dos salários intercalares, suscitanos algumas reservas na medida em que uma opção deste género pode significar, a prazo, um acréscimo de custos previsíveis para o Estado, considerando o já sobrecarregado sistema público de segurança social português.

Concluímos reforçando que, globalmente, as medidas propostas no âmbito da revisão do Código do Trabalho se pautam por uma clara opção por medidas de flexibilidade interna e que, acompanhada por um processo de diálogo social que a antecedeu - ainda que numa área jurídica em que as divergências filosóficas e políticas são muito acentuadas, se corra o risco de nunca agradar plenamente a todos - a presente revisão legislativa traduz a procura de um equilíbrio entre a realização de valores sociais inalienáveis, reconhecidos como fundamentais para a sociedade portuguesa, e as novas exigências de gestão e competitividade das empresas.

\section{NOTA FINAL}

O presente Working Paper - que serviu também de base para a elaboração de um Seminário e de uma Conferência organizadas pelo Dinâmia e subordinadas ao mesmo tema - foi redigido em Maio de 2008, a partir das propostas apresentadas pelo documento Reforma das Relações Laborais, apresentado pelo Governo em 22 de Abril de 2008, pelo não foram consideradas na sua análise as alterações posteriores alcançadas em sede de Concertação Social e que foram incluídas na redacção da Proposta Global final do documento de Revisão do Código do Trabalho. 


\section{REFERÊNCIAS BIBLIOGRÁFICAS}

ALMEIDA, P. P. (2004), "Servicialização do Trabalho: perspectivas e tendências”, Sociologia, Problemas e Práticas, nº 44, pp. 83-107.

ALMEIDA, P. P. e Rebelo, G. (2004), A Era da Competência - um novo paradigma para a Gestão de Recursos Humanos e o Direito do Trabalho, Lisboa, RHeditora.

BARTHÉLÉMY, J. (2003), "Conventions et accords colectifs: pour un vrai droit de leur négociaton”, Droit Social, nº 9/10, pp. 832-837.

BELOUS, R. S. (1989), The contingent Economy: the Growth of the Temporary, Part-time an Subcontract Workforce, Nova Iorque, National Planning Association.

CARNEVALE, A., et al (1998), "Contingent Workers and Employment Law”, in Barker, K. and $\mathrm{K}$.

CHRISTENSEN (org.), Contingent Work - American Employment Relations in Transition, Ithaca, IRL Press.

CHALMIN, P. (2004), Cyclope 2004: les marchés mondiaux, Paris, Economica.

CLBRL (2007), Livro Branco das Relações Laborais, Comissão do Livro Branco das Relações Laboral, Lisboa, Ministério do Trabalho e da Solidariedade Social.

COMISSÃO DAS COMUNIDADES EUROPEIAS (2006), Livro Verde - Modernizar o Direito do Trabalho para enfrentar os desafios do século XXI, COM 708 final, Bruxelas.

COMISSÃO DO LIVRO BRANCO DAS RELAÇÕES LABORAIS (2007), Livro Branco das Relações Laborais, Ministério do Trabalho e da Solidariedade Social. 
CONSELHO ECONÓMICO E SOCIAL (1996), Acordo de Concertação Estratégica 1996/1999, Lisboa, Conselho Económico e Social.

DAMAS J. A. D. (1997), “A redução da duração do trabalho e a adaptação dos horários na Lei 21/96”, Questões Laborais, n 9-10, pp. 90-114.

DORNELAS, A. (coord.) (2006), Livro Verde sobre as Relações Laborais, Ministério do Trabalho e da Solidariedade Social.

ESPING-ANDERSEN, G. (2000), “Um Estado-providência para o século XXI”, in Boyer, R., et al, Para uma Europa da Inovação e do Conhecimento, Oeiras, Celta.

EUROFOUND (2005), Forms of self-employment in Portugal Forms of self-employment in Portugal, Dublin, Eurofound EWCO.

EUROPEAN COMMISSION (2008), Economic Forecast - Spring 2008, Directorate-General for Economic and Financial Affairs, European Economy, $n^{\circ}$ 1/2008.

EUROSTAT (2007), "People in the labour market”, in Europe in Figures, Eurostat yearbook 2006/2007, pp. 131-146.

FELSTEAD, A. e N. Jewson (1999), Global Trends in flexible labour, Basingstoke, Macmillan. FITOUSSI, J. P. e P. Rosanvallon (1997), A Nova Era das Desigualdades, Oeiras, Celta.

GALLIE, D., et al, (1998), Restructuring the employment relationship, Oxford, Oxford University Press.

GONÇALVES, M. E. (2003), Direito da Informação - Novos Direitos e Modos de Regulação na Sociedade da Informação, Coimbra, Almedina.

GONÇALVES da Silva, L. (2001), "Da Eficácia Normativa das Convenções Colectivas”, in Estudos do Instituto de Direito do Trabalho, Coimbra, Almedina.

HART, H.L.A. (1961), The Concept of Law, Oxford, Oxford University Press.

INE (2007), Anuário Estatístico de Portugal 2006, Tema A - Estatísticas Multitemáticas, Lisboa, Instituto Nacional de Estatística.

MONTEIRO Fernandes, A. (2002), Um Rumo para as Leis Laborais, Coimbra, Almedina.

MONTEIRO Fernandes, A. (2004), Direito do Trabalho, Coimbra, Almedina.

MONTEIRO Fernandes, A. (2008), Trabalhos Leves - Crónicas, Coimbra, Almedina.

MOTA da Silva, I. (1998), “A intervenção do Estado na promoção da qualidade do trabalho”, in Direito do Trabalho - Memórias, $I^{\circ}$ Congresso Nacional de Direito do Trabalho, Coimbra, Almedina.

MTSS (2008), Reforma das Relações Laborais, Lisboa, Ministério do Trabalho e da Solidariedade Social.

PALMA M. R. Ramalho, (2003), Estudos de Direito do Trabalho, Coimbra, Almedina.

REBELO, G. (1999), A Inadaptação no Trabalho - Uma Perspectiva Socio-organizacional e Jurídica, Oeiras, Celta. 
REBELO, G. (2002a), "Flexibilidade ou precariedade? Alguns exemplos de formas de trabalho/emprego no contexto europeu”, in AAVV, Actas do IX Encontro da APSIOT, Oeiras, Celta.

REBELO, G. (2002b), Emprego e Formas de Precariedade da Actividade Laboral - o caso de Portugal no contexto da UE, Tese de Doutoramento, Instituto Superior de Economia e Gestão, Universidade Técnica de Lisboa.

REBELO, G. (2003), Trabalho Independente em Portugal, WP Dinâmia $n^{0}$ 32, Lisboa, Dinâmia/ISCTE.

REBELO, G. (2004), Flexibilidade e Precariedade no Trabalho - Análise e Diagnóstico, Lisboa, ed. autor co-financiada Fundação para a Ciência e Tecnologia (FCT) e Dinâmia/ISCTE.

REBELO, G. (2005a), "Emprego e Segurança Social: actualidade e tendências”, Sociedade e Trabalho, nº 26, pp. 81-92.

REBELO, G. (2005b), "Investimento e criação de emprego", Cadernos de Economia n ${ }^{0} 73$, Ordem dos Economistas, pp. 70-76.

REBELO, G. (2006a), “Alternativas à precariedade laboral: propostas para uma flexibilidade tendencialmente qualificante”, in Sociologia, Faculdade de Letras da Universidade do Porto, pp. 191-201.

REBELO, G. (2006b), "Desafios para uma revisão do Código do Trabalho”, in Jornal de Negócios, 4 de Dezembro.

REBELO, G. (2006c), “O PNACE 2005/2008: flexibilidade, educação e formação”, Cadernos de Economia $n^{\circ}$ 75, Ordem dos Economistas, pp. 68-72.

REBELO, G. (2006d), Flexibilidade e Diversidade Laboral em Portugal, WP Dinâmia nº 50, Lisboa, Dinâmia/ISCTE.

REBELO, G. (2007a), “Flexisegurança à espanhola”, in Jornal de Negócios, 22 de Janeiro.

REBELO, G. (2007b), "Modernizar o Direito do Trabalho (I)”, in Jornal de Negócios, 2 de Abril.

REBELO, G. (2007c), “Desemprego e verdades (in) convenientes”, in Jornal de Negócios, 4 de Junho.

REBELO, G. (2007d), "Modernizar o Direito do Trabalho (II)”, in Jornal de Negócios, 9 de Abril.

REBELO, G. (2007e), “Modernizar o Direito do Trabalho (III)”, in Jornal de Negócios, 16 de Abril.

REBELO, G. (2007f), “Modernizar o Direito do Trabalho (IV)”, in Jornal de Negócios, 23 de Abril.

REBELO, G. (2008), "Política Laboral e de Emprego: a questão europeia”, Autor, edição online de Março.

REBELO, G. (coord.) (2007d), "Igualdade de Oportunidades no Trabalho - Perspectiva de Género numa Sociedade Solidária”, Dinâmia/ISCTE para o CEFOSAP/UGT. 
RIBEIRO F. Lopes, (1998), “A contratação colectiva”, in Moreira, A. (org.), Direito do Trabalho $-I^{\circ}$ Congresso Nacional de Direito do Trabalho, Coimbra, Almedina.

ROMANO, P. Martinez, (2002), Direito do Trabalho, Coimbra, Almedina.

SOETE, L. (2000), “A economia baseada no conhecimento num mundo globalizado - desafios e potencial”, in Boyer, R., et al, Para uma Europa da Inovação e do Conhecimento, Oeiras, Celta.

SPYROPOULOS, G. (2002), "Le droit du travail à la recherche de nouveaux objectifs", Droit Social, $n^{\circ}$ 4, pp. 391-403.

SUPIOT, A. (org.) (1999), Au-delà de l'Emploi. Transformations du Travail et Devenir du Droit du Travail en Europe, Paris, Flammarion.

VERDINKT, P. Y. (1995), "Le principe d'egalité de traitement aux travailleurs précaires", Droit Social, $\mathrm{n}^{\circ}$ 3, pp. 870 e segs. 